\title{
Lung function in white children aged 4 to 19 years: II-Single breath analysis and plethysmography
}

\author{
M Rosenthal, D Cramer, S H Bain, D Denison, A Bush, J O Warner
}

\begin{abstract}
Objective-A study was performed to determine reference ranges for whole body plethysmographic gas volumes and single breath gas transfer in healthy prepubertal and pubertal schoolchildren.

Methods-The study was performed in 772 white London schoolchildren (455 male) who were clinically examined, assessed auxologically and, in $63 \%$ of cases, pubertally staged. Regression equations for the calculation of standard deviation scores were derived.

Results-Male lung function variables showed a discontinuous pattern of increase with standing height. Linear increases until puberty were followed by a sudden pubertal rise and a further increase with height which was more marked than before puberty. Correction for varying thoracic dimensions eliminated these changes. In females a smoother curvilinear relationship was observed with no correction possible for thoracic size.

Conclusions-Male puberty leads to profound changes in pulmonary function mostly related to thoracic size, an effect not observed in females.
\end{abstract}

(Thorax 1993;48:803-808)

This paper is concerned with whole body plethysmographic measurement of thoracic gas volumes and the assessment of both func-

Department of Paediatric

Respiratory Medicine,

Royal Brompton

National Heart and

Lung Hospital,

London SW3 6NP

$M$ Rosenthal

D Cramer

S H Bain

D Denison

A Bush

Department of Child

Health, University of

Southampton,

Southampton, General

Hospital,

Southampton

$\mathrm{J} O$ Warner

Reprint requests to:

Dr A Bush

Received 7 January 1993

Returned to authors

14 April 1993

Revised version received

22 April 1993

Accepted 27 April 1993 by a single breath technique in healthy white UK schoolchildren. Spirometeric measurements have been dealt with in the previous paper. ${ }^{1}$

Only two studies on normal lung function from the UK have reported measurements of transfer factor, ${ }^{23}$ and there have been three British reports on values of thoracic gas volumes, ${ }^{24-6}$ although one of these ${ }^{2}$ used closed circuit helium dilution rather than plethysmography to assess lung volumes.

As with spirometric measurements it is important to have reference data for the adolescent period, often previously neglected, particularly with the increasing survival time of children with chronic lung diseases. Spirometric values exhibit a profound change during puberty which cannot be described by simple linear or curvilinear equations ${ }^{1}$ as quoted currently. It may also be inappropriate to quote a standard deviation (SD) about a regression line if the degree of data dispersion about that mean varies systematically with stature. This would render the "percentage predicted" results (actual result - predicted result) $/ 100 \%$ ) meaningless. In order to overcome this difficulty and to allow easier comparison of differing lung function variables, we propose the use of an SD score calculated as (actual result - predicted result)/ population SD.

\section{Methods}

The children have been fully described elsewhere ${ }^{1}$ but briefly comprised 772 white schoolchildren of UK origin (455 male) from

Table 1 Calculation of the predicted result for males using a linear equation of intercept $A$ and slope $B \times$ standing height in cm. $R^{2}$ represents the percentage variance predicted by the linear equation and $D$ represents the standard deviation as a fraction of the predicted result. (For worked example, see Appendix.)

\begin{tabular}{|c|c|c|c|c|c|}
\hline & Height & $A$ & $B$ & $R^{2}$ & $D$ \\
\hline TLCo $(\mathrm{mmol} / \mathrm{min} / \mathrm{kPa})$ & $\begin{array}{l}<162 \cdot 6 \\
>162 \cdot 5\end{array}$ & $\begin{array}{l}-3 \cdot 99 \\
-19 \cdot 0\end{array}$ & $\begin{array}{l}0 \cdot 070 \\
0 \cdot 173\end{array}$ & $\begin{array}{l}98 \\
93\end{array}$ & $0.043+(0.0008 \times \mathrm{Ht})$ \\
\hline VA (1) & $\begin{array}{l}<162 \cdot 6 \\
>162 \cdot 5\end{array}$ & $\begin{array}{l}-3 \cdot 490 \\
-9 \cdot 785\end{array}$ & $\begin{array}{l}0.04357 \\
0.0867\end{array}$ & $\begin{array}{l}97 \\
97\end{array}$ & $0 \cdot 11$ \\
\hline $\begin{array}{l}\text { TLCo/VA } \\
(\mathrm{mmol} / \mathrm{min} / \mathrm{kPa} / \mathrm{l})\end{array}$ & $\begin{array}{l}<162 \cdot 6 \\
>162.5\end{array}$ & $\begin{array}{l}4 \cdot 13 \\
2 \cdot 10\end{array}$ & $\begin{array}{l}-0.013 \\
0\end{array}$ & $\begin{array}{l}81 \\
93\end{array}$ & $0 \cdot 11$ \\
\hline FRC (1) & $\begin{array}{l}<162 \cdot 6 \\
>162 \cdot 5\end{array}$ & $\begin{array}{l}-1 \cdot 716 \\
-7 \cdot 036\end{array}$ & $\begin{array}{l}0.02394 \\
0.05918\end{array}$ & $\begin{array}{l}97 \\
96\end{array}$ & $0.341-(0.0012 \times \mathrm{Ht})$ \\
\hline TLC (l) & $\begin{array}{l}<162 \cdot 6 \\
>162.5\end{array}$ & $\begin{array}{l}-3 \cdot 828 \\
-10 \cdot 648\end{array}$ & $\begin{array}{l}0 \cdot 04976 \\
0 \cdot 09586\end{array}$ & $\begin{array}{l}98 \\
99\end{array}$ & $0 \cdot 12$ \\
\hline RV (1) & $\begin{array}{l}<162 \cdot 6 \\
>162 \cdot 5\end{array}$ & $\begin{array}{l}-0.283 \\
-3.905\end{array}$ & $\begin{array}{l}0.00818 \\
0.03095\end{array}$ & $\begin{array}{l}91 \\
97\end{array}$ & $0 \cdot 28$ \\
\hline $\operatorname{Raw}(\mathrm{kPa} / / \mathrm{s})$ & $\begin{array}{l}<162 \cdot 6 \\
>162 \cdot 5\end{array}$ & $\begin{array}{l}0.634 \\
0.36\end{array}$ & $\begin{array}{l}-0.0026 \\
-0.0012\end{array}$ & $\begin{array}{l}36 \\
69\end{array}$ & 0.65 \\
\hline
\end{tabular}

TLCo-carbon monoxide transfer factor; VA—accessible lung volume; FRC—functional residual capacity; TLC—total lung capacity; RV-residual volume; Raw-airways resistance. 

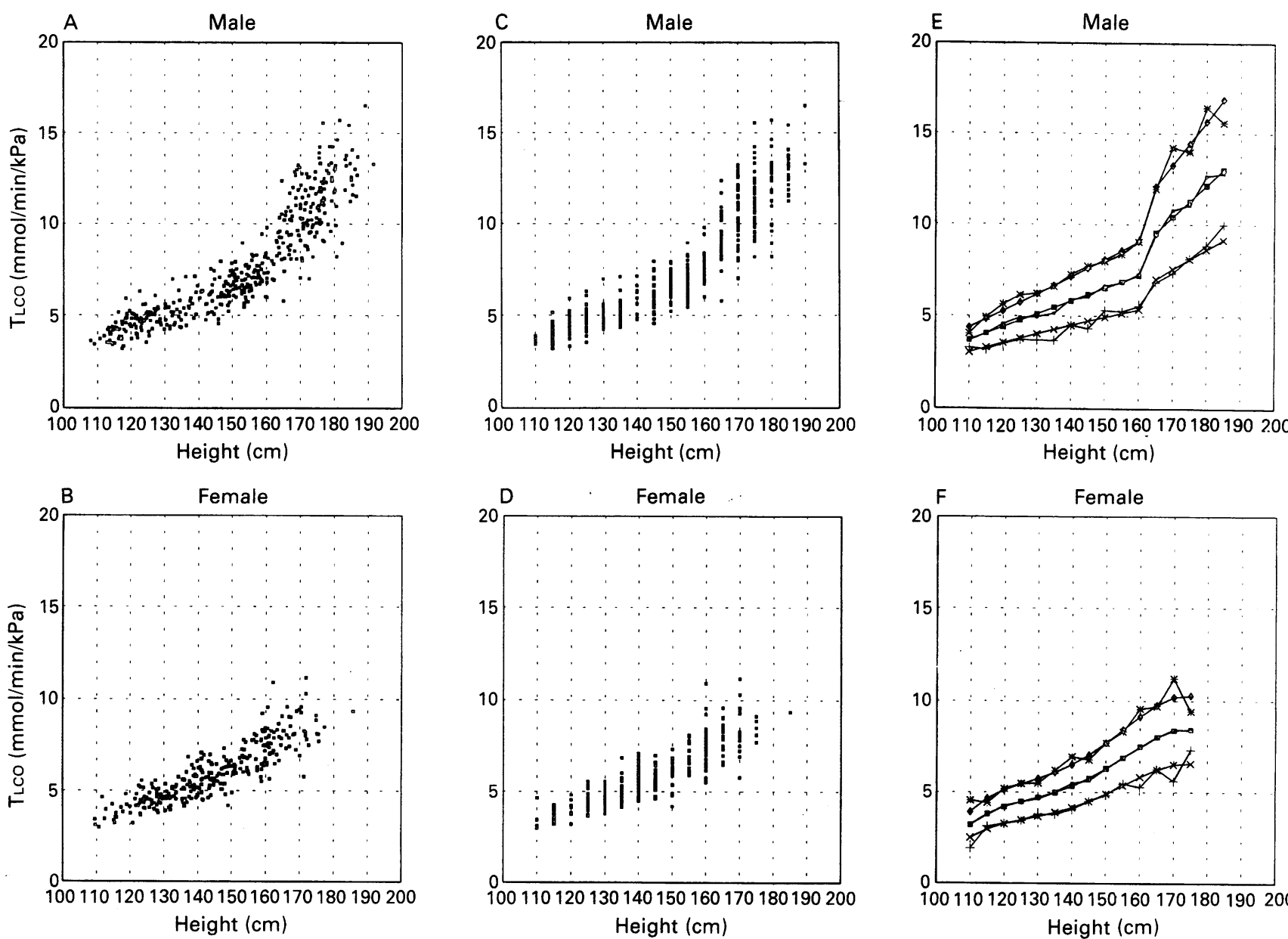

- Tukey mean, - Regression lines

,$+ x-2 S D$ raw, fitted results

*, +2SD raw, fitted results

Figure 1 Raw data for TLCO in (A) males and (B) females aginst exact standing height, or $(C)$ males and (D) females grouped in $5 \mathrm{~cm}$ height blocks (note the discontinuity in values at $165 \mathrm{~cm}$ in males but no discontinuity in females), Tukey mean (2SD) for each height block with the fitted mean and $S D$ lines derived from tables 1 and 2 for $(E)$ males and $(F)$ females.

12 London schools, free from recent acute or chronic conditions. They received detailed auxological measurements and permission was obtained to assess puberty in $81 \%$ of girls over 8 years and $61 \%$ of boys over 10 years by the method of Tanner. ${ }^{7}$

\section{TRANSFER FACTOR AND ACCESSIBLE LUNG VOLUME}

Using a transfer factor apparatus model B (PK Morgan, Rainham, UK), the seated child inhaled to total lung capacity (TLC), exhaled to residual volume (RV), and inspired a single breath of gas (composition $0.28 \%$ carbon monoxide, $14 \%$ helium, balance air) back to TLC, holding the breath for 10 seconds. After the breath hold the exhaled gas was sampled and the transfer factor (TLCO) and accessible lung volume (VA) Oo were calculated. ${ }^{5}$ Inline thermocouple and ambient pressure and temperature measurements, simultaneously recorded, permitted the expression of the transfer factor at STPD and the alveolar volume at BTPS.

Table 2 Calculation of predicted results in females where $A, B, C, E, F$ and $G$ represent the coefficients of a fifth power fraction of the predicted result. (For worked example, see Appendix.)

\begin{tabular}{|c|c|c|c|c|}
\hline & Height & $A$ & $B$ & $C$ \\
\hline TLCo $(\mathrm{mmol} / \mathrm{min} / \mathrm{kPa})$ & $110-175$ & $-577 \cdot 13$ & $16 \cdot 781$ & $-0 \cdot 1811017$ \\
\hline VA (1) & $110-175$ & $-289 \cdot 408$ & $8 \cdot 43755$ & -0.091267633 \\
\hline TLCo/VA $(\mathrm{mmol} / \mathrm{min} / \mathrm{kPa} / \mathrm{l})$ & $110-175$ & $4 \cdot 14$ & -0.013 & 0 \\
\hline FRC (1) & $110-175$ & -33.928 & $1 \cdot 14780$ & -0.0136745 \\
\hline TLC (1) & $110-175$ & $-234 \cdot 078$ & $7 \cdot 03067$ & -0.07802979 \\
\hline RV (1) & $110-175$ & $610 \cdot 323$ & $-20 \cdot 91427$ & $0 \cdot 28586128$ \\
\hline $\operatorname{Raw}(\mathrm{kPa} / \mathrm{l} / \mathrm{s})$ & $110-175$ & $0 \cdot 7$ & -0.0031 & 0 \\
\hline$(T L C-V A) / T L C$ & $120-175$ & $0 \cdot 321$ & -0.00104 & 0 \\
\hline
\end{tabular}

For definition of abbreviations see footnote to table 1 . 
THORACIC GAS VOLUMES, AIRWAY RESISTANCE, AND DEAD SPACE

Children were seated in a whole body plethysmograph (Pulmostar SMB, Fenyves and Gut, Basle, Switzerland) used to estimate functional residual capacity (FRC) and airway resistance (Raw) at FRC. They breathed from a 50 litre bag fully saturated with water vapour at $37^{\circ} \mathrm{C}$ via a Fleisch pneumotachograph model $\mathrm{C}$. The effects of gastrointestinal gas were assumed to be insignificant. All other gas volumes were calculated from the FRC value. Thus, total lung capacity (TLC) was the sum of FRC and inspiratory reserve volume measured from the pneumotachograph, and residual volume (RV) was the difference between the FRC and expiratory reserve volume. All results are expressed at BTPS. The fractional dead space was estimated as ((TLC - VA)/TLC). The KCO (Krogh factor) was estimated as TLCO/VA. The lung function protocol for both methods conformed to EEC standards for entry criteria, equipment, and methodology.$^{89}$

\section{STATISTICAL ANALYSIS}

All techniques employed have been previously described in the paper on spirometry ${ }^{1}$ to which the reader is referred, in particular for the description concerning the attribution of normality to a variable. Essentially, children of each sex were grouped in $5 \mathrm{~cm}$ height blocks and, for each variable, a robust measure of the mean of each height block and its SD were derived. These robust means had regression lines fitted and a further regression equation was calculated for the $\mathrm{SD}$ of the variable.

Correction factors for pubertal stage were derived to refine an SD score where necessary. Individual results are expressed as mean and $95 \%$ confidence intervals.

\section{Results}

Although $97 \cdot 7 \%$ of the 772 children were able to perform a satisfactory single breath manoeuvre and $98.4 \%$ performed a satisfactory plethysmographic manoeuvre for gas volumes, only $86 \%$ managed the airway resistance manoeuvres successfully.

The attribution of normality to a particular variable was less clear cut than with the spirometric measurements as only $80 \%$ of the tests failed to detect departure from normality compared with more than $90 \%$ for spirometry. ${ }^{1}$ Numerous logarithmic and power transformations did not improve the situation so untransformed data were used in all cases.

The distribution of the heights and pubertal stages of the children are shown in the paper on spirometry. ${ }^{1}$ The distribution of TLCO with height in each sex is shown in fig $1 \mathrm{~A}$ and $\mathrm{B}$ whilst fig $1 \mathrm{C}$ and $\mathrm{D}$ shows the same results collated into $5 \mathrm{~cm}$ height blocks. In males there is a sharp discontinuity in the relationship at $165 \mathrm{~cm}$ as TLCO accelerates with increasing height.

This discontinuity parallels that observed with spirometry at the same height. By contrast girls in this study do not show a discontinuity at $155 \mathrm{~cm}$ as observed with spirometry. ${ }^{1}$ Tukey weighted means (2SD) of results shown in fig $1 C$ and $D$, together with their fitted regression lines from tables 1 and 2 , are plotted in fig $1 \mathrm{E}$ and $\mathrm{F}$. For males two linear equations are used: the first for boys of height $107 \cdot 6-162.5 \mathrm{~cm}$ and the second for those of height $162 \cdot 6-187 \cdot 5 \mathrm{~cm}$. For females a single polynomial equation was used for all girls of $107 \cdot 6-177.5 \mathrm{~cm}$ in height. Tables 1 and 2 summarise sex specific equations for calculating an individual SD based on height alone. The results of all other variables are summarised in fig $2 \mathrm{~A}-\mathrm{N}$.

\section{EFFECT OF GENDER}

Except for TLCO, VA and TLC, there was no difference between the sexes in children under a height of $162.5 \mathrm{~cm}$ for the variables measured. TLCO was $6 \cdot 6 \%(3 \cdot 9-9 \cdot 3 \%)$ greater in boys than in girls whilst VA was $5 \cdot 7 \% \quad(1 \cdot 4-10 \cdot 0 \%)$ and TLC $3.6 \%$ $(0 \cdot 2-7 \cdot 1 \%)$ greater in boys below $162.5 \mathrm{~cm}$ in height. In children taller than $162.6 \mathrm{~cm}$ all values of variables were less in girls than in boys, with a tendency for this difference to increase with increasing height.

\section{EFFECT OF PUBERTY}

The effects of puberty on single breath and plethysmographic results was less obvious than on spirometric measurements. ${ }^{1}$ In girls there was no obvious discontinuity around the time of puberty compared with that seen in males. TLCO, VA, KCO, TLC, and FRC in particular tended to increase at a particular height in boys measuring $162.6-175.5 \mathrm{~cm}$, progressing from pubertal stage 3 to stage 5 (table 3). In shorter males, however, no such

polynomial, $R^{2}$ represents the variance explained by the regression equation, and $D$ represents the standard deviation as a

\begin{tabular}{lllll}
\hline$E$ & $F$ & $G$ & $R^{2}$ & $D$ \\
\hline 0.0008636953 & $-1.5287 \times 10^{-6}$ & 0 & 100 & $0 \cdot 11$ \\
$4 \cdot 351045553 \times 10^{-4}$ & $-7.649615 \times 10^{-7}$ & 0 & 99 & $0 \cdot 11$ \\
0 & 0 & 0 & 97 & $0 \cdot 0068+(0 \cdot 00073 \times \mathrm{Ht})$ \\
$6.98227757 \times 10^{-5}$ & $-1 \cdot 2725216 \times 10^{-7}$ & 0 & 99 & $0 \cdot 17$ \\
$3 \cdot 8100528 \times 10^{-4}$ & $-6 \cdot 8597971 \times 10^{-7}$ & 0 & 98 & $0 \cdot 12$ \\
$-1.94588828 \times 10^{-3}$ & $6.594203 \times 10^{-6}$ & $-8 \cdot 8899 \times 10^{-9}$ & 97 & $0 \cdot 28$ \\
0 & 0 & 0 & 79 & $0 \cdot 55$ \\
0 & 0 & 0 & 62 & $0 \cdot 74-(0.00286 \times \mathrm{Ht})$ \\
\hline
\end{tabular}



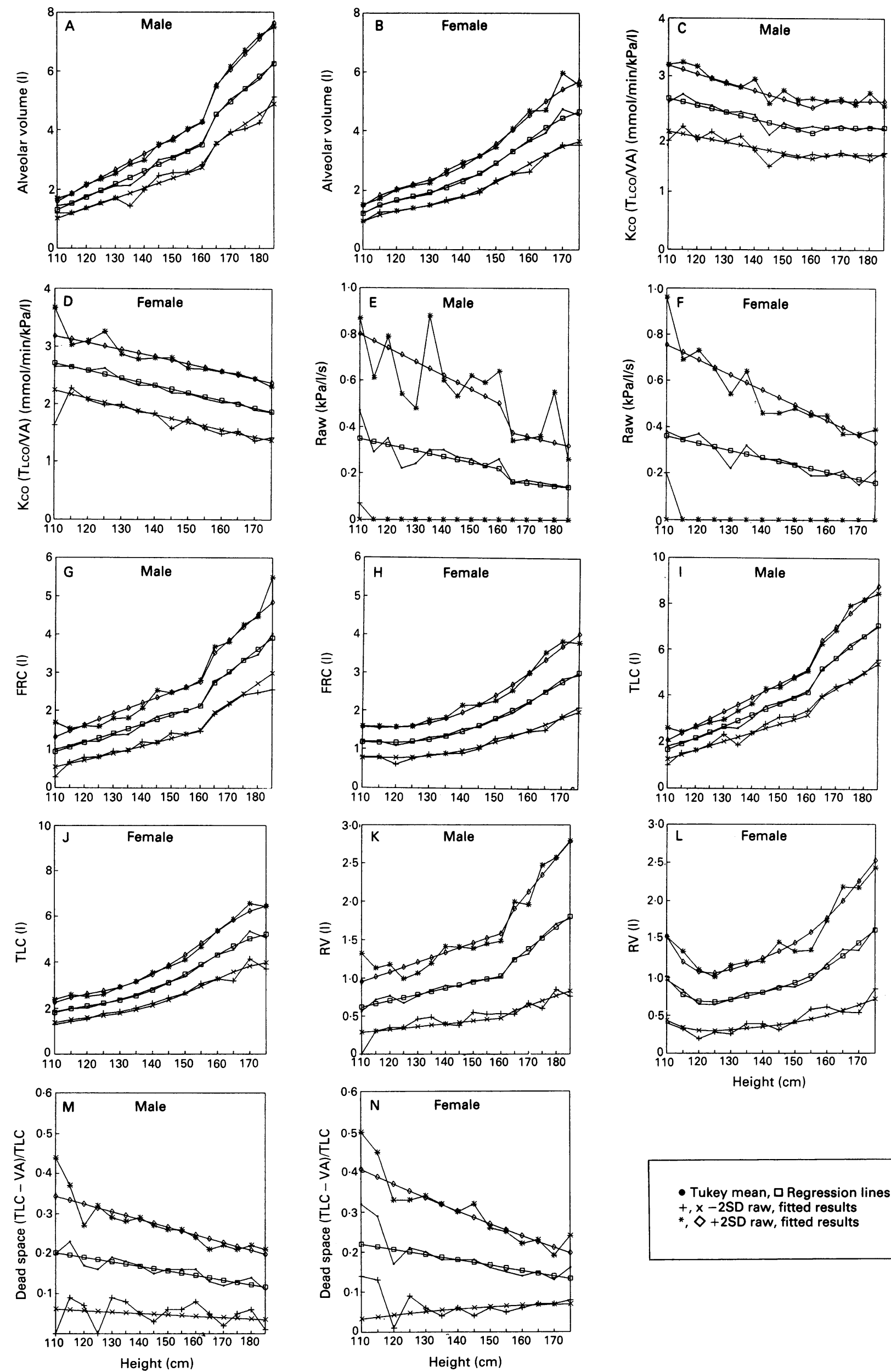

- Tukey mean, $\square$ Regression lines

,$+ x-2 S D$ raw, fitted results

$*, \diamond+2 S D$ raw, fitted results

Figure $2 A-N$ Tukey mean (2SD) results in males and females together with fitted mean and SD lines derived from tables 1 and 2 for the single breath and plethysmographic results and their derived ratios (Kco and dead space). 
Table 3 Mean SD scores for variables by pubertal stage in boys $162 \cdot 6-175 \cdot 5 \mathrm{~cm}$ in height

\begin{tabular}{|c|c|c|c|}
\hline & \multicolumn{3}{|l|}{ Pubertal stage } \\
\hline & 3 & 4 & 5 \\
\hline TLCo & $-1 \cdot 16^{\star(0.32,2 \cdot 36)}$ & $0 \cdot 18$ & 0.30 \\
\hline VA & $-2 \cdot 48^{\star(0.85,3.59)}$ & -0.26 & $0 \cdot 28^{\star \star(-0.02,1 \cdot 0)}$ \\
\hline Kco & -0.72 & $0 \cdot 1$ & 0.2 \\
\hline FRC & $-1 \cdot 90^{\star(0.23,2.95)}$ & -0.31 & 0.23 \\
\hline TLC & $-1 \cdot 93^{\star(0 \cdot 72,3 \cdot 02)}$ & -0.06 & $0.42^{\star \star(-0.06,1.02)}$ \\
\hline
\end{tabular}

* $(a, b)$ Significant difference $(p<0.05)$ between puberta stages 3 and 4 and $95 \%$ confidence limits for the difference between the means; $\star \star(a, b)$ significant difference $(p<0.05)$ between pubertal stages 4 and 5 and the $95 \%$ confidence limits for the difference between the means. For definition of abbreviations see footnote to table 1 .

trend was apparent. Figure 3 shows a comparison of the TLCO data in this study with the most recent UK standards presented by Cotes et al. ${ }^{2}$ The results compare well up to adolescence, after which our own results are considerably higher.

\section{EFFECT OF BODY FRAME}

To investigate whether a constant relationship existed between estimates of thoracic volume and pulmonary function we examined various auxological indices which might proportionately reflect thoracic volume. The sitting height (as an estimate of thoracic length) and the square of chest circumference or chest depth in inspiration or expiration (as a measure of thoracic area) were used to test whether the ratio of pulmonary function (any variable) to thoracic volume was constant.

In males this was true over the entire height range for the square of the chest circumference $\times$ sitting height (table 4 ) and was identical to that described for spirometric variables. ${ }^{1}$ In females, however, no relationship could be derived which produced a similar constant. In particular, primary pulmonary function variable/the square of chest depth in inspiration $\times$ sitting height, which had been appropriate for spirometric vari-

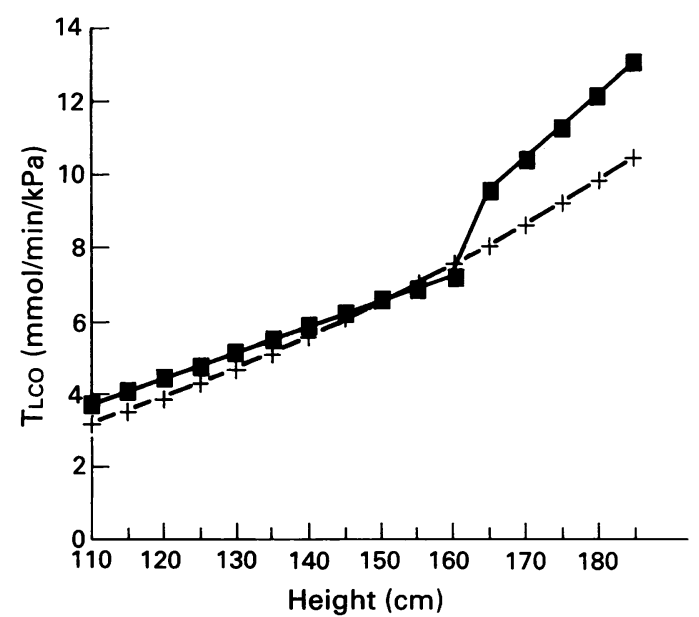

Current -+- Cotes (1979)

Figure 3 Comparison of current relationship of TLCO with height against that of the most recent previous $U K$ study by Cotes et al (1979).
Table 4 Mean (95\% confidence interval) and SD of lung function variable/chest circumference at maximum inspiration ${ }^{2} \times$ sitting height in male children $(n=389)$ with all auxological measurements in metres

\begin{tabular}{lcl}
\hline & Mean (95\% confidence interval) & $S D$ \\
\hline TLCo & $15.9(15.7$ to 16.1$)$ & 2.3 \\
VA & $7.13(7.06$ to $7 \cdot 20)$ & 0.72 \\
FRC & $4.52(4.44$ to 4.60$)$ & 0.82 \\
TLC & $8.47(8.38$ to 8.56$)$ & 0.92 \\
RV & $2.34(2.27$ to $2 \cdot 41)$ & 0.75 \\
\hline
\end{tabular}

For definition of abbreviations see footnote to table 1 .

ables, was associated with a significant negative correlation with standing height in this study.

\section{Discussion}

The purpose of this study was to derive pulmonary function reference data for children aged 4 to 19 years, especially during puberty and adolescence, which might prove useful for the assessment of those who now survive chronic lung disease into this period. For males, in particular, we have shown that puberty results in a dramatic change in almost all lung variables-for example, TLCO is $75 \%$ greater in a child $150 \mathrm{~cm}$ tall than in a child $110 \mathrm{~cm}$ in height, and $250 \%$ greater at $190 \mathrm{~cm}$. This pattern is repeated for VA and plethysmographic gas volumes. Although similar patterns have been observed by us in the accompanying paper and by others in spirometric measures, ${ }^{10}$ they have not previously been noted to occur with other lung function variables. Together these data would suggest that it is important to consider prepubertal and postpubertal children separately, and that a single linear or curvilinear equation cannot adequately describe the data.

Similar explanations may account for these changes in males in puberty as were put forward for the identical pattern observed with spirometry in the accompanying paper. Peak changes in lung function may occur up to 18 months after the peak somatic growth spurt. ${ }^{11}$ Thoracic length increases disproportionately to standing height and, in contrast to females, there is also an increase in thoracic width. ${ }^{12}$ These changes will thus result in a greater fractional increase in thoracic volume than in height.

We are unable to explain the apparent absence of a pubertal effect on lung function in females in contrast to the situation we observed in our study on spirometry. However, the curvilinear relationship accords with the work of Sherill et al who also found a synchronous increase in thoracic volume and somatic growth in girls but not boys. ${ }^{11}$ The pubertal effect observed on spirometry in females, as in males, may possibly result from the relatively greater contribution of muscle strength (which increases in puberty) to forced ventilatory manoeuvres necessary for spirometric techniques, rather than the more passive techniques used in the measurement of thoracic volume. We observed no difference in chest depth on maximum inspiration or expiration between the sexes which might have accounted for these discrepancies. 
The high RV noted in shorter girls (fig $2 \mathrm{~L}$ ) is probably the result of subject error in performance technique since these girls were also the youngest. Nevertheless, the results have not been adjusted to account for this since similar results are likely to be obtained on repetition of the test in any clinical setting Although fractional dead space was also higher in the same (short) girls, however, these results have been adjusted in order to avoid a needlessly complex fitted equation.

In accord with the work of other authors ${ }^{213}$ we also observed a decline in $\mathrm{KCO}$ with increasing height. However, this trend arrested with the onset of puberty in boys. The observations of others ${ }^{1415}$ who did not describe a similar relationship may have been limited by smaller subject numbers.

We believe that, as with paediatric growth charts, longitudinal lung function charts present the ideal method for following children with chronic lung disease. Furthermore, the calculation of standard deviation scores is superior to percentage predicted results as it eliminates changes in dispersion with changing stature. We hope the present data will prove useful in these respects.

\section{Appendix}

$$
\text { SD score }=\frac{\text { Actual result }- \text { Predicted result }}{\text { Population standard deviation }}
$$

Worked example from table 1

Male $170 \mathrm{~cm}$, TLCO $=7 \mathrm{mmol} / \mathrm{min} / \mathrm{kPa}$

$$
\begin{aligned}
\text { SD score } & =\frac{7-(-19 \cdot 0+(0.173 \times 170))}{\left(\begin{array}{l}
0.043+(0.0008 \times 170)) \\
-19 \cdot 0+(0.173 \times 170))
\end{array}\right)} \\
& =-1.83
\end{aligned}
$$

From table 3 the above SD score can be corrected. Thus, for pubertal stage 3, score $=$ $-1.83-(-1 \cdot 16)=-0.67$; for pubertal stage 5 , score $=-1 \cdot 83-0 \cdot 30=-2 \cdot 13$.

Worked example from table 2

Female $160 \mathrm{~cm}$, TLC $=4$ litres.

Predicted result $=$

$$
\begin{aligned}
& -234 \cdot 078+(7 \cdot 03067 \times 160) \\
& -\left(0 \cdot 07802979 \times 160^{2}\right) \\
& +\left(3 \cdot 8100528 \times 10^{-4} \times 160^{3}\right) \\
& -\left(0.00000068597971 \times 160^{4}\right) \\
& =4.300 \text { litres }
\end{aligned}
$$

$\mathrm{SD}=0.12 \times 4.300=0.516$ litres

SD score $=\frac{4 \cdot 0-4 \cdot 3}{0.516}=-0.581$

NB. (a) Do not round coefficients as this will lead to significant errors. (b) Do not use thr equations outside the height range of $t$ sample population.

1 Rosenthal M, Bain SH, Cramer D, Helms P, Denison I Bush A, et al. Lung function in white children aged 4 19 years: I-Spirometry. Thorax 1993;48:794-802.

2 Cotes JE, Dabbs JM, Hall AM, Heywood C, Lawrenci KM. Sitting height, fat free mass and body fat as reference variables for lung function in healthy British children: comparison with stature. Ann Hum Biol 1979; 6:307-14.

3 Strang LB. Measurements of pulmonary diffusing capacity in children. Arch Dis Child 1960;35:232-5.

4 Cogswell J, Hull D, Milner AD, Norman AP, Taylor B. Lung function in childhood 2 . Thoracic gas volume and helium functional residual capacity measurements in healthy children. Br f Dis Chest 1975;69:118-24.

5 Cogswell JJ, Hull D, Milner AD, Norman AP, Taylor B. 3. Measurement of airflow resistance in healthy children. Br $\mathcal{F}$ Dis Chest 1975;69:177-87.

6 Godfrey S, Kamburoff PL, Nairn JR. Spirometry, lung volumes and airway resistance in normal children aged 5-18 years. BrF Dis Chest 1970;64:15-24.

7 Tanner JM. Growth at adolescence. 2nd edn. Oxford: Blackwell, 1962.

8 European Community for Coal and Steel. Standardisation of lung function tests. Bull Eur Physiopathol Respir 1983;19(Suppl 5):11-21.

9 European Community for Coal and Steel. Standardisation of lung function tests. Bull Eur Physiopathol Respir 1983;19(Suppl 5):39-44

10 Dickman ML, Schmidt CD, Gardner RM. Spirometric standards for normal children and adolescents (ages 5 years through 18 years). Am Rev Respir Dis 1971; 104:680-7.

11 Sherrill DL Camilli A, Lebowitz MD. On the temporal relationship between lung function and somatic growth. Am Rev Respir Dis 1989;140:638-44.

12 DeGroodt EG, van Pelt W, Borsboom GJJM, Quanjer $\mathrm{PH}$, van Zomeren BC. Growth of lung and thorax dimensions during the pubertal growth spurt. Eur Respir f 1988:1:102-8.

13 Zalpetal A, Samanek M, Paul T. Lung function in chil dren and adolescents. Methods and reference values. Prog Respir Res 1987;22:83-112.

14 DeMuth GR, Howatt WF. The growth of lung function: pulmonary diffusion. Pediatrics 1965;35(Suppl 3): 185-93.

15 Nasr SZ, Amato P, Wilmott RW. Predicted values for lung diffusing capacity in healthy children. Pediatr Pulmonol 1991;10:267-72. 